\title{
Securitização de Recebíveis - Análise dos Riscos Inerentes
}

\author{
Fernando Antonio Perrone Pinheiro* \\ José Roberto Ferreira Savoia**
}

\section{Resumo}

A securitização é uma modalidade de estruturação financeira em que uma empresa obtém recursos diretamente no Mercado de Capitais através da cessão de seus recebíveis. No Brasil, a securitização vem se desenvolvendo na forma dos fundos de investimento em direitos creditórios, que captam recursos através da emissão de cotas seniores, adquiridas por investidores qualificados, e de cotas subordinadas, usualmente adquiridas pelo originador dos créditos. Este artigo avalia os riscos e os retornos para os investidores, através de um modelo de simulação estocástica das variáveis taxas de juros e taxas de inadimplência, considerando também as características do fundo, tais como o percentual de cotas subordinadas, tipo de ativo securitizado e proporção de recebíveis sobre o ativo total do fundo. Os resultados obtidos indicam que, para o investidor em cotas sênior, é altamente improvável a obtenção de retorno inferior à taxa indicativa do fundo. Para o investidor em cotas subordinadas, o risco de retorno inferior à taxa de juros é baixo, em decorrência dos spreads praticados no mercado financeiro brasileiro. As simulações realizadas indicam também que, em níveis normais de volatilidade das taxas de juros, as perdas de crédito são a componente principal do risco das cotas. Dentro do conjunto das análises desenvolvidas observou-se que as exigências de capital dos bancos que securitizam ativos e carregam cotas subordinadas em seu balanço é bastante conservadora, em comparação com os padrões internacionais.

Palavras-chave: securitização; FIDC; recebíveis; direitos creditórios; risco de crédito; operações estruturadas.

Códigos JEL: G20; G28; G32; G33.

\section{Abstract}

Securitization is a modality of structured finance which allows a company to raise funds based on its receivables through capital markets. In Brazil, securitization was developed mostly in the form of mutual funds - the FIDC, which raise money by issuing senior cotes for qualified investors, and subordinated cotes, usually bought by the company that originated the receivables. This paper evaluates the risk and return for both kinds of investors through a stochastic model with two main variables: interest rates and default rates. The

Submetido em Janeiro de 2009. Aceito em Junho de 2009. O artigo foi avaliado segundo o processo de duplo anonimato além se de ser avaliado pelo editor. Editor responsável: Newton Costa Jr.

* Mestre em Administração pela Faculdade de Economia, Administração e Contabilidade da Universidade de São Paulo. Professor da Fundação Instituto de Administração. E-mail: fap.pinheiro@terra.com.br

**Professor Doutor da Universidade de São Paulo, Professor e Consultor do Fundação Instituto de Administração e Membro do Brazil Study Group e Membro do GDN da Columbia University. E-mail: jrsavoia@usp.br 
model is still sensible to the characteristics of the fund, like the amount of subordinated cotes, the type of asset being securitized; and the amount of receivables in relation to the assets. Regarding the case of senior cotes, the risk of returns under the basic level of interest rates is highly improbable; and in the case of subordinated cotes, the risk of returns under the basic interest rate may be considered still low, due to the high spreads observed in the Brazilian financial market. The simulations indicated that under historically mean interest rate volatility the default rates are the main component of the total risk. Accordingly to the developed analysis of international standards of regulation, the Brazilian Central Bank imposes very strong capital requirements to banks that securitize their assets and purchase the corresponding subordinated cotes.

Keywords: securitization; FIDC; receivables; credit risk; structured finance.

\section{Introdução}

Os Fundos de Investimentos em Direitos Creditórios, ou FIDC, foram introduzidos ao final de 2001, pela Resolução CMN n 2907. O ativo desses fundos são direitos creditórios, ou seja, direitos representativos de crédito, originários de operações realizadas nos segmentos financeiro, comercial, industrial, imobiliário e de prestação de serviços. Os FIDC captam através da emissão de cotas que se subordinam entre si quanto ao pagamento para o investidor, denominadas cota sênior e cota subordinada. De acordo com estatísticas da ANBID, o patrimônio líquido dos FIDC superou os 44 bilhões de reais em junho de 2008, o que corresponde a $3,79 \%$ da indústria de fundos. Segundo Ferreira (2007, p. 47), a expansão desses fundos deve ser creditada, em parte, à liquidação extrajudicial do Banco Santos, pois instituições pequeno e médio porte passaram a utilizar essa estrutura para financiar seus ativos.

A securitização apresenta riscos, como qualquer outra modalidade de investimento. Rosenthal e Ocampo (1988, p. 17) citam que os agentes reguladores tendem a ver a securitização com cautela devido a duas razões: em primeiro lugar, com a ênfase em originar ativos, bancos podem perder o incentivo a manter a disciplina na concessão de crédito, o que pode elevar o risco dos sistemas financeiros; e em segundo, com a venda das operações de crédito, reduz-se o impacto das normas que visem adequar o capital das instituições e de outras medidas prudenciais. $\mathrm{Na}$ economia americana, a Crise do Subprime evidenciou esses riscos.

Este artigo irá mostrar que o risco dos FIDC para o investidor em cotas sênior é consideravelmente baixo e é altamente provável que ele obtenha retorno igual à taxa indicativa do fundo. Para o investidor em cotas subordinadas, geralmente adquiridas pela companhia que originou os recebíveis, o risco de que o retorno seja inferior à taxa de juros básica da economia é baixo, graças aos elevados spreads praticados no mercado financeiro brasileiro. Serão analisadas também as regras de suficiência patrimonial dos bancos que adquirem cotas subordinadas, tendo em vista o risco que essas representam. 


\section{Benefícios Advindos da Securitização}

A securitização oferece inúmeros benefícios às economias, o que justifica o desenvolvimento deste mercado nos EUA a partir dos anos 70. A securitização proporciona às empresas o acesso direto ao mercado de capitais para captar recursos para o financiamento de seus ativos; favorece a competitividade no mercado de crédito, pois representa uma alternativa de captação para os bancos de menor porte; e reduz os riscos do sistema bancário, já que parte do risco é transferida ao investidor.

A Figura 1 apresenta um resumo das principais vantagens para o originador e para o investidor.

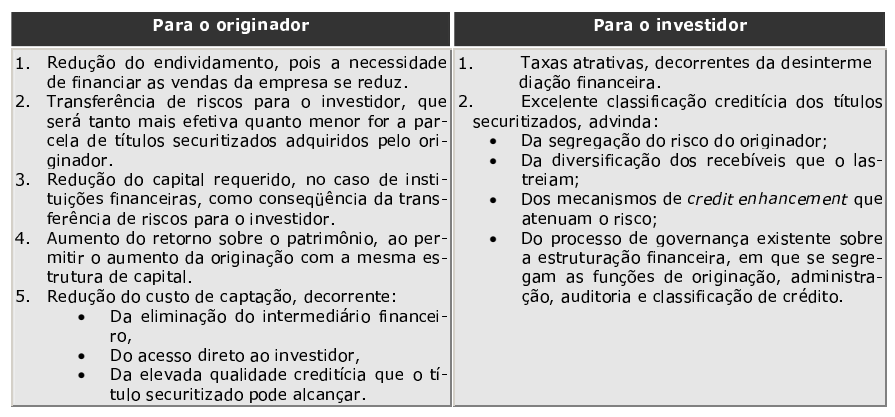

Figura 1

Benefícios da securitização para o originador e para o investidor

Os benefícios da securitização para o tomador de crédito são perceptíveis no longo prazo: Rosenthal e Ocampo (1988, p. 12) citam que, com o advento da securitização, os tomadores de crédito imobiliário nos EUA passaram a pagar 100 pontos-base a menos. Este benefício é facilmente explicável: a securitização proporciona uma maior competitividade no mercado de crédito, pois bancos de menor porte adquirem a capacidade de captar recursos a um custo menor. Isto decorre da possibilidade de emissão de títulos de elevado rating, superior inclusive à classificação obtida pelo próprio banco. Desta forma, a securitização possibilita a redução dos spreads no longo prazo. Bodie et alii (2000, p. 35) lembram também que a securitização proporcionou uma melhor distribuição dos recursos para financiamento imobiliário nos EUA. Este benefício torna-se mais relevante quando os bancos possuem caráter regional. 


\section{Fortalecimento da Qualidade Creditícia}

O fortalecimento da qualidade creditícia, ou "credit enhancements" constituise em prática que possibilita compatibilizar o nível de risco do título ao apetite para o risco do investidor. Fabozzi Jr. et alii (2006, p. 104) citam os seguintes métodos de enhancement: a vinculação de carta de crédito, a incorporação de uma apólice de seguro de crédito, a existência de excess spread entre as taxas de remuneração do ativo e do passivo, a sobrecolaterização, e as estruturas de senioridade e subordinação.

Os FIDC existentes no Brasil estão estruturados com cotas seniores e cotas subordinadas. Assim, cotas seniores são aquelas que não se subordinam às demais quando do pagamento de amortização e resgate do ativo securitizado; cotas subordinadas são aquelas cujo pagamento de amortização e resgate está subordinado à cota sênior, ou à cota subordinada que the precede. Em outras palavras: o administrador do fundo, ao receber os pagamentos decorrentes das operações de crédito da carteira do fundo, amortiza e remunera a cota sênior em primeiro lugar; havendo recursos, ele irá amortizar e remunerar a cota subordinada.

É importante notar que a remuneração-alvo estabelecida em uma securitização não se constitui em garantia de remuneração, mas apenas um indicativo. Esta remuneração indicativa é estabelecida para os níveis sênior e demais níveis intermediários (mezaninos), se existirem, mas não para o nível júnior, também conhecido como equity, já que este nível recebe todos os recursos que excederem os pagamentos feitos aos níveis superiores. Os FIDC estruturados no Brasil comumente estabelecem a remuneração-objeto na forma pós-fixada, indexada à taxa dos Certificados de Depósitos Interfinanceiros de um dia.

\section{Riscos Inerentes à Securitização}

Uma vez que o retorno de qualquer estrutura de securitização depende da liquidação dos recebíveis adquiridos, o risco de crédito constitui-se em importante fator de risco para os investidores que adquirem cotas de FIDC. A inadimplência dos ativos afeta primeiramente o investidor em cotas subordinadas; se a inadimplência se eleva, o retorno desse investidor reduz-se até o ponto em que todo o capital investido é perdido. Nessa situação, o investidor em cotas sênior passa a arcar com as perdas.

Existem outras fontes de risco: considerando que os ativos que servem de lastro aos FIDC são pré-fixados em sua grande maioria, e que a remuneração indicativa das cotas sênior é indexada ao CDI, verifica-se a existência de um descasamento entre o ativo e o passivo do fundo. Considere-se a hipótese de que as taxas do CDI subam extraordinariamente: nesta situação, os haveres do investidor em cotas subordinadas serão drenados para o pagamento da remuneração indicativa do nível de maior subordinação. Logo, volatilidade das taxas de juros também é variável a considerar no risco dos FIDC. 
Existem outros riscos na securitização de ativos. Carneiro e Goldfajn (2000) citam o risco de preço, decorrente da conveniência do tomador em não pagar sua dívida quando o valor da mesma supera o valor do bem financiado; o risco de liquidez, que é fruto dos descasamentos do fluxo de caixa; o risco de pré-pagamento, que implica na redução da rentabilidade do ativo; e o risco sistêmico, também citado por Ranieri (1996, p. 33), proveniente de um aumento generalizado da inadimplência a ponto de comprometer a solvência dos agentes financeiros. Kothari (2006, p. 195-234) elenca adicionalmente o risco cambial, que ocorre quando o ativo é indexado à moeda estrangeira; os riscos operacionais, decorrentes das atividades desempenhadas por todas as partes envolvidas, como entidade originadora, servicers, administrador do fundo, etc; e o risco de seleção adversa do portfólio, também citado por Greenbaum e Thakor (1987), que consiste na manutenção dos piores ativos na carteira do originador. Para efeitos deste artigo, serão considerados apenas o risco de taxa de juros e o risco de inadimplência.

\section{Metodologia Utilizada}

\subsection{Modelo de simulação estocástico}

A avaliação dos riscos das cotas sênior e subordinada será feita através da utilização de modelo de simulação estocástica, conhecido também como Modelo de Simulação Monte Carlo, ou Monte Carlo Estruturado - MCE. Este modelo baseia-se no movimento browniano geométrico, em que os retornos não são autocorrelacionados e seguem uma distribuição normal.

$$
d S_{t}=\mu_{t} S_{t} d t+\sigma_{t} S_{t} d z(\text { Jorion, 1998, p. 222) }
$$

onde:

$S_{t}$ é o valor do ativo no instante $t$;

$u_{t}$ é o retorno médio em $t$;

$\sigma_{t}$ é o valor do desvio-padrão dos retornos em $t$;

$d z$ é uma variável aleatória normalmente distribuída com média $=0$ e desvio padrão $=1$. 
As variáveis simuladas serão a taxa de juros e a taxa de inadimplência. Adaptando-se a equação acima ao objetivo pretendido, faz-se $d y_{t}=\sigma_{y t} y_{t} d z$, onde $d y_{t}$ é o diferencial de taxa de juros no instante " $t$ " e $\sigma_{y t}$ é o desvio-padrão de suas variações. As simulações irão gerar caminhos aleatórios tanto para juros como para inadimplência, a serem aplicados a uma estrutura de securitização padrão, onde serão calculados os retornos das cotas seniores e subordinadas. Como estas simulações envolvem 2 variáveis, faz-se necessário manter as correlações existentes entre as mesmas, o que é feito com o uso da decomposição de Cholesky.

\subsection{Seleção das variáveis}

Foram utilizados dados de conhecimento público, divulgados nos websites de órgãos ligados ao mercado financeiro. Assim:

- As informações sobre os FIDC existentes, como forma de estruturação, classificação creditícia, remuneração das cotas etc, foram obtidas na CVM, ANBID e agências de rating;

- A taxa de juros considerada foi o CDI mensal, expresso na forma anual, ano base de 252 dias úteis. A taxa média do CDI de 1 dia é calculada e divulgada pela CETIP. A série em questão, obtida no Banco Central, é denominada "CDI acumulado no mês anualizado", número de referência 4392, de agosto a dezembro de 2007.

As séries de inadimplência, obtidas junto ao Banco Central, foram calculadas para as diversas modalidades de operações de crédito na modalidade recursos livres, entre junho de 2000 e dezembro de 2007. Os ativos financeiros objetos de estudo, comumente alvos de securitização no Brasil, são: o crédito pessoal, a aquisição de bens e os títulos mercantis. As séries escolhidas estão apontadas na Tabela 1 . 
Tabela 1

Séries do Banco Central do Brasil utilizada

\begin{tabular}{|c|c|c|c|c|c|c|c|}
\hline \multirow[b]{2}{*}{$\begin{array}{l}\text { Tipo de } \\
\text { pessoa }\end{array}$} & \multirow[b]{2}{*}{ Modalidade } & \multicolumn{4}{|c|}{$\mathrm{N}^{0}$ de série $\mathrm{p} /$ saldos } & \multirow[b]{2}{*}{$\begin{array}{c}\mathrm{N}^{\circ} \text { de série } \\
\mathrm{p} / \text { taxa de juros }\end{array}$} & \multirow[b]{2}{*}{$\begin{array}{c}\mathrm{N}^{\circ} \text { de série } \\
\mathrm{p} / \text { prazo médio }\end{array}$} \\
\hline & & $\begin{array}{c}\text { Saldo } \\
\text { sem atraso }\end{array}$ & $\begin{array}{c}\text { Saldos com atraso } \\
\text { de } 15 \text { a } 30 \mathrm{~d}\end{array}$ & $\begin{array}{c}\text { Saldos com atraso } \\
\text { de } 31 \text { e } 90 \mathrm{~d}\end{array}$ & $\begin{array}{c}\text { Saldos com atraso } \\
\text { maior que } 90 \mathrm{~d}\end{array}$ & & \\
\hline \multirow{3}{*}{$\begin{array}{l}\text { Pessoa } \\
\text { física }\end{array}$} & Crédito pessoal & 871 & 872 & 873 & 874 & 3947 & 880 \\
\hline & Aquisição de bens veículos - PF & 972 & 973 & 974 & 975 & 3948 & 981 \\
\hline & Aquisição de outros bens - PF & 1023 & 1024 & 1025 & 1026 & 3949 & 1032 \\
\hline \multirow{2}{*}{$\begin{array}{l}\text { Pessoa } \\
\text { jurídica }\end{array}$} & Desconto de duplicatas & 502 & 503 & 504 & 505 & 3940 & 511 \\
\hline & Capital de giro & 524 & 525 & 526 & 527 & 3942 & 533 \\
\hline
\end{tabular}


Da Tabela 1, os saldos das operações de crédito sem atraso, com atraso entre 15 e 30 dias, entre 31 e 90 dias, e superior a 90 dias permitem que se calcule a taxa de inadimplência cumulativa, que relaciona créditos em atraso com o valor da carteira.

Considerações sobre as taxas de inadimplência: para as faixas de atraso com intervalos temporais homogêneos, isto é, atrasos até 30 dias, de 31 a 60 dias, de 61 a 90 dias etc, as taxas de inadimplência deveriam ser decrescentes quanto maior fosse o atraso, pois se espera que parte dos créditos em atraso seja recuperada a cada período. De fato, a leitura é mais complexa em função da desigualdade entre os intervalos e em função das normas de classificação e provisionamento de créditos:

- A taxa de inadimplência superior a 90 dias pode conter créditos em atraso por até 360 dias, ainda não lançados a prejuízo, e não pode ser considerada como parâmetro para avaliar novos créditos em atraso.

- As estatísticas de atraso entre 31 e 90 dias podem apresentar uma deficiência: uma operação de crédito cujo atraso supere os 31 dias será apontada duplamente nas estatísticas do Banco Central, porque ela poderá sensibilizar as estatísticas por dois meses consecutivos.

- As estatísticas de atraso entre 15 e 30 dias podem também apresentar problemas, pois um crédito em atraso de poucos dias poderá não sensibilizar esta estatística, e no mês subseqüente estará sensibilizando a estatística de atrasos entre 31 e 90 dias.

- Não se pode deixar de notar também que as taxas de inadimplência apresentam o viés de se reduzirem quando ocorre o aumento de carteira, e viceversa.

Para efeitos de estimação das perdas de crédito, serão consideradas as estatísticas de atraso entre 31 e 90 dias, mesmo que esta premissa seja mais conservadora e venha a superestimar os riscos, sob determinadas circunstâncias. Assim, para efeitos de cálculo da perda financeira proveniente da inadimplência, será adotado:

$$
p=1-\left(1-\frac{d_{31 a 90}}{1-d_{>90}}\right)^{\frac{360}{\text { prazo medio }}}
$$

onde:

$p=$ taxa de perda por inadimplência, expressa na forma anual; $d_{31 a 90}=$ taxa de inadimplência entre 31 e 90 dias;

$d_{>90}=$ taxa de inadimplência superior a 90 dias. 


\subsection{Análise das variáveis}

As séries estudadas de taxa de juros e taxa de inadimplência compreenderam o período de janeiro de 2002 a dezembro de 2007. A Tabela 2 apresenta a estatística descritiva e teste de normalidade para estas variáveis. Note-se que a normalidade não pode ser rejeitada (H0) para nenhuma das séries, pois o teste de KolmogorovSmirnov aponta $Z<Z_{\text {crítico }}=1,3581$.

Tabela 2

Estatística descritiva das variações do CDI mensal e das taxas de inadimplência de diferentes ativos financeiros

\begin{tabular}{l|c|c|c|c|c|c}
\hline \multirow{2}{*}{ Ativo } & \multirow{2}{*}{$\begin{array}{c}\text { Variação } \\
\text { da taxa }\end{array}$} & \multicolumn{5}{c}{ Variação das taxas de inadimplência } \\
\cline { 3 - 7 } & do CDI Mensal & $\begin{array}{c}\text { Crédito } \\
\text { pessoal }\end{array}$ & $\begin{array}{c}\text { CDC Veí́culos } \\
\text { PF }\end{array}$ & $\begin{array}{c}\text { CDC } \\
\text { Outros PF }\end{array}$ & $\begin{array}{c}\text { Desconto de } \\
\text { duplicatas }\end{array}$ & $\begin{array}{c}\text { Capital } \\
\text { de giro }\end{array}$ \\
\hline $\mathrm{N}$ & 72 & 72 & 72 & 72 & 72 & 72 \\
\hline Mínimo & $-0,1122$ & $-0,1908$ & $-0,198$ & $-0,2197$ & $-0,4924$ & $-0,627$ \\
\hline Máximo & 0,0877 & 0,1499 & 0,1749 & 0,2655 & 0,5355 & 0,4502 \\
\hline Média & $-0,0075$ & $-0,0188$ & $-0,0039$ & $-0,0041$ & $-0,0049$ & $-0,0171$ \\
\hline Desvio Padrão & 0,0345 & 0,0669 & 0,0643 & 0,1005 & 0,1641 & 0,1623 \\
\hline Assimetria & 0,3147 & $-0,0078$ & $-0,0962$ & 0,8039 & 0,414 & $-0,3574$ \\
\hline Curtose & 2,2657 & 0,553 & 0,7733 & 0,6998 & 3,4427 & 2,2874 \\
\hline Kolmogorov-Smirnov Z & 1,2293 & 0,8007 & 0,4347 & 1,0706 & 0,9831 & 0,672 \\
\hline Significância & 0,0974 & 0,5429 & 0,9916 & 0,2018 & 0,2885 & 0,7572 \\
\hline
\end{tabular}

Os fatores de risco foram testados também para se verificar a independência entre os mesmos. Adotou-se o CDI mensal como variável independente e inadimplência como variável dependente. A Tabela 3 a seguir apresenta o sumário do modelo e os testes, visando verificar a existência de uma relação linear entre as variáveis.

Tabela 3

Regressão linear entre o CDI mensal e as taxas de inadimplência

\begin{tabular}{|c|c|c|c|c|c|c|}
\hline \multicolumn{2}{|c|}{ Estatística } & $\begin{array}{l}\text { Crédito } \\
\text { pessoal }\end{array}$ & $\begin{array}{c}\text { CDC veículos } \\
\text { PF }\end{array}$ & $\begin{array}{c}\text { CDC } \\
\text { outros PF }\end{array}$ & $\begin{array}{c}\text { Desconto de } \\
\text { duplicatas }\end{array}$ & $\begin{array}{l}\text { Capital } \\
\text { de giro }\end{array}$ \\
\hline \multicolumn{2}{|c|}{ R múltiplo } & 0,1095 & 0,1202 & 0,2029 & 0,0237 & 0,0882 \\
\hline \multicolumn{2}{|l|}{$\mathrm{R}^{2}$} & 0,012 & 0,0144 & 0,0412 & 0,0006 & 0,0078 \\
\hline \multicolumn{2}{|l|}{$\mathrm{R}^{2}$ ajustado } & $-0,0021$ & 0,0004 & 0,0275 & $-0,0137$ & $-0,0064$ \\
\hline \multicolumn{2}{|l|}{ Erro padrão } & 0,0669 & 0,0642 & 0,0991 & 0,1652 & 0,1628 \\
\hline \multicolumn{2}{|c|}{$\mathrm{N}^{0}$ de observações } & 72 & 72 & 72 & 72 & 72 \\
\hline \multirow[t]{2}{*}{ Anova } & $\mathrm{F}$ & 0,8489 & 1,0255 & 3,0056 & 0,0394 & 0,5494 \\
\hline & Significância & 0,36 & 0,3147 & 0,0874 & 0,8432 & 0,461 \\
\hline \multirow[t]{2}{*}{ Coeficientes } & Interseção & $-0,0172$ & $-0,0022$ & 0,0003 & $-0,0057$ & $-0,014$ \\
\hline & Variável & 0,2124 & 0,2241 & 0,5917 & $-0,113$ & 0,4157 \\
\hline \multirow[t]{2}{*}{ Estatística P } & Interseção & 0,0367 & 0,7764 & 0,9783 & 0,7743 & 0,4792 \\
\hline & Variável & 0,36 & 0,3147 & 0,0874 & 0,8432 & 0,461 \\
\hline
\end{tabular}

Note-se que os resultados da Tabela 3 indicam não haver correlação ou relação linear entre a taxa de juros e as taxas de inadimplência, pois a significância do teste F e a significância do teste $P$ para o coeficiente angular mostraram-se elevados; e o valor do coeficiente de determinação $R^{2}$ está muito próximo de zero.

Testou-se também a hipótese de existência de correlação quando as variáveis estão defasadas. Sob o ponto de vista econômico, é razoável afirmar que o encarecimento do custo de financiamento em " $t+0$ ” venha a gerar uma elevação da 
inadimplência em " $t+n$ ", pois a elevação da taxa de juros provoca um aumento de ônus sobre o tomador de crédito. A Tabela 4 apresenta a correlação quando se introduz uma defasagem entre as variáveis.

Tabela 4

"Cross correlation" para a variação das taxas de inadimplência

\begin{tabular}{c|c|c|c|c|c}
\hline $\begin{array}{c}\text { Defasagem } \\
\text { (meses) }\end{array}$ & $\begin{array}{c}\text { Crédito } \\
\text { pessoal }\end{array}$ & $\begin{array}{c}\text { CDC } \\
\text { veículos PF }\end{array}$ & $\begin{array}{c}\text { CDC } \\
\text { Outros PF }\end{array}$ & $\begin{array}{c}\text { Desconto de } \\
\text { duplicatas }\end{array}$ & $\begin{array}{c}\text { Capital } \\
\text { de Giro }\end{array}$ \\
\hline-6 & $-0,175$ & $-0,193$ & $-0,205$ & 0,061 & $-0,026$ \\
\hline-5 & $-0,099$ & $-0,177$ & $-0,114$ & $-0,017$ & $-0,016$ \\
\hline-4 & $-0,045$ & $-0,072$ & $-0,037$ & $-0,008$ & $-0,021$ \\
\hline-3 & $-0,045$ & $-0,059$ & 0,041 & $-0,192$ & $-0,016$ \\
\hline-2 & 0 & $-0,045$ & 0,041 & $-0,185$ & 0,014 \\
\hline-1 & 0,09 & 0,11 & 0,108 & $-0,073$ & 0,047 \\
\hline 0 & 0,109 & 0,12 & 0,203 & $-0,024$ & 0,088 \\
\hline 1 & 0,105 & 0,098 & 0,106 & $-0,087$ & 0,014 \\
\hline 2 & 0,108 & 0,16 & 0,065 & 0,02 & 0,083 \\
\hline 3 & 0,161 & 0,181 & 0,142 & 0,084 & 0,215 \\
\hline 4 & 0,042 & 0,108 & 0,066 & $-0,007$ & 0,053 \\
\hline 5 & 0,118 & 0,087 & $-0,03$ & 0,018 & $-0,024$ \\
\hline 6 & 0,052 & 0,011 & $-0,144$ & 0,062 & 0,023 \\
\hline
\end{tabular}

Pela imaterialidade das correlações é desnecessário o uso da Decomposição de Cholesky e as variáveis podem ser simuladas independentemente.

\subsection{Parametrização das simulações}

Para a realização de simulações sobre o risco dos FIDC, é necessário estabelecer uma série de parâmetros, alguns deles baseados em observações das práticas de mercado, outros em dados econométricos sobre taxas de juros e taxa de perda. Estes parâmetros são:

a) Fortalecimento de crédito: passivo estruturado com apenas 1 nível de subordinação, com cotas subordinadas representando $15 \%$ do total de cotas.

b) Custos fixos: considerado $2 \%$ do patrimônio líquido do fundo.

c) Remuneração das cotas seniores: considerado taxa do CDI + 1,00 \% a.a., o que equivale a 109,4\% do CDI, para uma taxa básica de 11,25\% a.a.

d) Prazos: adotados prazos semelhantes àqueles praticados nas operações de crédito estudadas. Não se considerou a reposição dos ativos, o que elimina a necessidade de reapreçamento dos mesmos pela mudança de cenário. A Tabela 5 apresenta os prazos médios praticados, baseado nos dados do Banco Central do Brasil, e os prazos adotados para efeito de simulação. Considerese também que todos os ativos e passivos têm vencimentos idênticos. 
Tabela 5

Prazos simulados

\begin{tabular}{l|c|c}
\hline \multicolumn{1}{c|}{ Modalidades } & $\begin{array}{c}\text { Prazo médio } \\
\text { das carteiras }(*)\end{array}$ & $\begin{array}{c}\text { Prazos considerados nas simulações } \\
\text { (prazo 1 e prazo 2) }\end{array}$ \\
\hline Crédito pessoal & 15,3 meses & 24 e 48 meses \\
\hline CDC Veículos PF & 19,7 meses & 24 e 48 meses \\
\hline CDC outros PF & 6,6 meses & 6 e 12 meses \\
\hline Desconto de duplicatas & 1,3 mês & 2 e 4 meses \\
\hline Capital de giro & 9,4 meses & 12 e 24 meses \\
\hline * Fonte: BACEN
\end{tabular}

e) Recuperação de crédito: não se considerou recuperação de crédito. O parâmetro definido como "perda por inadimplência", que na verdade foi deduzido a partir das taxas de inadimplência, despreza a recuperação.

f) Volatilidades: calculadas com base no modelo EWMA - exponential weighted moving average, com lambda $=0,94$.

$$
\sigma=\sqrt{(1-\lambda) \sum_{t=1}^{T} \lambda^{t-1}\left(\xi_{t}-\bar{\xi}\right)^{2}} \text { (Longerstaey e Spencer, 1996, p. 78) }
$$

Para o cálculo das volatilidades, os retornos para taxa de juros e de inadimplência foram calculados fazendo-se $\xi_{t}=\ln \left(y_{t} / y_{t-1}\right)$, onde $y_{t}$. é a taxa no momento " $t$ " e $\xi_{t}$ a variação desta taxa entre os instantes " $t$ " e " $t-1$ ".

g) Taxas utilizadas: considerado como mês base dezembro de 2007. Assim: - CDI mensal inicial: considerado que a taxa do CDI é igual à meta da taxa SELIC em dezembro de 2007, ou seja, $11,25 \%$ a.a. Taxas das operações de crédito, taxas de perda por inadimplência e respectivas volatilidades: calculadas para o mês base de dezembro de 2007. Estes parâmetros estão resumidos na Tabela 6.

Tabela 6

Parâmetros utilizados para as operações de crédito

\begin{tabular}{l|c|c|c}
\hline \multicolumn{1}{c|}{ Modalidades } & $\begin{array}{c}\text { Taxa para as } \\
\text { operações de crédito }\end{array}$ & $\begin{array}{c}\text { Taxa de perda } \\
\text { por inadimplência }\end{array}$ & $\begin{array}{c}\text { Volatilidade } \\
\text { da taxa de perda }\end{array}$ \\
\hline & (\% a.a.) & $(\%$ a.a.) & \\
\hline CDI Mensal & - & - & $2,67 \%$ \\
\hline Crédito pessoal & $45,80 \%$ & $1,86 \%$ & $6,37 \%$ \\
\hline CDC Veículos PF & $28,76 \%$ & $2,21 \%$ & $5,68 \%$ \\
\hline CDC outros PF & $56,53 \%$ & $9,18 \%$ & $10,33 \%$ \\
\hline Desconto de duplicatas & $32,30 \%$ & $7,11 \%$ & $10,90 \%$ \\
\hline Capital de giro & $27,92 \%$ & $1,58 \%$ & $12,70 \%$ \\
\hline
\end{tabular}

Fonte: Banco Central do Brasil - mês base: dezembro de 2007.

h) Composição da carteira: foram considerados fundos com 100\% e com 50\% de operações de crédito sobre o ativo total. Além dos ativos securitizados, 
os fundos mantêm parte da sua posição em títulos públicos com o objetivo de mitigar o risco de liquidez proveniente dos descasamentos do fluxo de caixa. Quanto maior o percentual destes títulos, menor a rentabilidade do fundo, mas menores são as perdas com inadimplência. Nas simulações, considerou-se que estes títulos são pós-fixados e remunerados a base de $100 \%$ do CDI. Em diversos regulamentos pesquisados, um fundo pode ser liquidado antecipadamente se essa relação cair abaixo de $50 \%$.

Foram realizadas simulações para cada uma das 5 modalidades de operações de crédito incluídas neste estudo. Fazendo-se permutar os parâmetros de prazo e composição da carteira, têm-se o bloco de simulações definido no Quadro 1, no qual foram apontados 20 tipos de simulação, e cada um baseia-se em uma modalidade de operação, um parâmetro de prazo e um parâmetro de composição de carteira. Para cada tipo, foram gerados aleatoriamente 2.000 cenários. Portanto, o número total de simulações realizadas para cada bloco compreende a:

5 modalidades de operação de crédito $\times 2$ parâmetros de prazo $\times$ 2 parâmetros de composição de carteira $\times 2.000$ simulações $=40.000$ simulações

\begin{tabular}{c|c|c|c}
\multicolumn{5}{c}{ Quadro 1 - Bloco de parâmetros de simulação } \\
\hline $\begin{array}{c}\text { Modalidade de } \\
\text { operação de crédito }\end{array}$ & $\begin{array}{c}\text { Prazo } \\
\text { (meses) }\end{array}$ & $\begin{array}{c}\text { \% de recebíveis } \\
\text { na composição do ativo }\end{array}$ & $\begin{array}{c}\text { Tipo de } \\
\text { Simulação }\end{array}$ \\
\hline Crédito pessoal & 24 & $100 \%$ & 1 \\
& 48 & $100 \%$ & 2 \\
& 24 & $50 \%$ & 3 \\
& 48 & $50 \%$ & 4 \\
\hline CDC Veículos PF & 24 & $100 \%$ & 5 \\
& 48 & $100 \%$ & 6 \\
& 24 & $50 \%$ & 7 \\
& 48 & $50 \%$ & 8 \\
\hline CDC outros PF & 6 & $100 \%$ & 9 \\
& 12 & $100 \%$ & 10 \\
& 6 & $50 \%$ & 11 \\
\hline Desconto de duplicatas & 12 & $50 \%$ & 13 \\
& 2 & $100 \%$ & 14 \\
& 2 & $100 \%$ & 15 \\
& 4 & $50 \%$ & 16 \\
\hline Capital de giro & 12 & $50 \%$ & 18 \\
& 24 & $100 \%$ & 19 \\
& 12 & $100 \%$ & 20 \\
\hline
\end{tabular}

Os resultados foram apresentados na forma cupom sobre a taxa do CDI, isto é, taxa do CDI + juros anuais, e não no formato "percentual do CDI", comumente utilizado pelo mercado. Os resultados estão dispostos em tabelas contendo: o percentil $1 \%$ e o retorno médio para cota sênior; os percentis $1^{\circ}, 2 \%, 5 \%$ e $10 \%$, os quartis $1^{\circ}, 2^{\circ}$ e $3^{\circ}$ e média para cota subordinada. 


\section{Aspectos Regulatórios do Setor Bancário}

Bancos securitizam os empréstimos e financiamentos que originam e adquirem as cotas subordinadas de seus fundos com o intuito de viabilizá-los. As cotas seniores são colocadas junto a investidores qualificados.

O Bank For International Settlements - BIS reconheceu, na revisão de seu Acordo de Capital, que o banco cedente exclua os ativos securitizados da base de capital se algumas condições forem satisfeitas, como:

- Parte significativa do risco de crédito tiver sido transferida a terceiros;

- Os ativos estiverem legalmente isolados do patrimônio do banco cedente;

- Os títulos emitidos não se constituam em obrigação do banco cedente;

- O cessionário é uma SPC e seus titulares têm o direito de negociá-los ou penhorá-los;

- A cessão de crédito não contenha cláusulas que impõem ao banco originador: assumir o primeiro impacto das perdas; elevar a taxa de desconto sobre os recebíveis como conseqüência da deterioração da qualidade dos ativos; e altere posteriormente à cessão a composição dos ativos, visando elevar a média da qualidade de crédito da carteira de recebíveis.

O BIS estabeleceu também fatores de ponderação conservadores baseados no rating dos instrumentos subordinados ou, na hipótese de inexistência desta avaliação, no nível de subordinação do título, na classificação creditícia do lastro, nas linhas de liquidez existentes, etc. Nas situações mais desfavoráveis, o banco deve deduzir de sua base patrimonial todo o ativo em títulos subordinados.

O Banco Central do Brasil adotou um enfoque mais restritivo para o cálculo do capital requerido: ao invés de considerar o risco implícito nas cotas subordinadas, o banco deve manter em seu ativo as operações de crédito securitizadas, como se a estruturação não houvesse ocorrido ( $\S 3^{\circ}$ do Artigo $1^{\circ}$ da Circular $\mathrm{n}^{\circ} 3360$ de 12/09/2007 e Artigos $2^{\circ}$ e $5^{\circ}$ da Resolução CMN n 3533 de 31/01/2008). Na prática, esta medida significa que o banco não se beneficia da operação de securitização, no tocante ao capital regulamentar.

\section{Análise dos resultados}

Foram realizados 4 blocos de simulação: o Bloco I considerou os parâmetros atuais de taxa de juros, de perdas e respectivas volatilidades; no Bloco II aumentouse a volatilidade da taxa de juros em 100\%; o Bloco III considerou os parâmetros do Bloco I, exceto pelo aumento de 50\% nas volatilidades das taxas de inadimplência; e no Bloco IV também considerou os parâmetros do Bloco I, mas elevou-se a taxa de inadimplência em 50\%. Os blocos II, III e IV consideram, portanto, fatores de stress. 
A Tabela 7 mostra que o cotista sênior teria recebido a remuneração indicativa de CDI + $1 \%$ a.a. com $99 \%$ de certeza em todos os tipos de simulação. O mesmo ocorre com a remuneração do cotista subordinado com a exceção da simulação 16 (ativo composto por $50 \%$ de duplicatas, com prazo de 4 meses), cujo retorno foi de CDI - $3 \%$ a.a. no percentil $1 \%$.

Tabela 7

Resultado da simulação - bloco I

\begin{tabular}{|c|c|c|c|c|c|c|c|c|c|c|}
\hline \multirow{3}{*}{$\begin{array}{c}\text { Tipo } \\
\text { de } \\
\text { simulação }\end{array}$} & \multicolumn{2}{|c|}{$\begin{array}{c}\text { Cota } \\
\text { sênior }\end{array}$} & \multicolumn{8}{|c|}{$\begin{array}{c}\text { Cota } \\
\text { subordinada }\end{array}$} \\
\hline & \multirow{2}{*}{$\begin{array}{c}\text { Percentil } \\
1 \%\end{array}$} & \multirow{2}{*}{ Média } & \multicolumn{4}{|c|}{ Percentil } & \multicolumn{3}{|c|}{ Quartil } & \multirow[b]{2}{*}{ Média } \\
\hline & & & $1 \%$ & $2 \%$ & $5 \%$ & $10 \%$ & $1^{\circ}$ & $2^{\circ}$ & $3^{0}$ & \\
\hline 1 & $1,00 \%$ & $1,00 \%$ & $105,50 \%$ & $107,20 \%$ & $109,60 \%$ & $111,80 \%$ & $115,10 \%$ & $118,50 \%$ & $121,80 \%$ & $118,20 \%$ \\
\hline 2 & $1,00 \%$ & $1,00 \%$ & $77,00 \%$ & $79,70 \%$ & $81,70 \%$ & $83,30 \%$ & $85,90 \%$ & $88,40 \%$ & $90,40 \%$ & $87,90 \%$ \\
\hline 3 & $1,00 \%$ & $1,00 \%$ & $55,10 \%$ & $56,60 \%$ & $58,30 \%$ & $59,90 \%$ & $62,00 \%$ & $64,20 \%$ & $66,30 \%$ & $64,10 \%$ \\
\hline 4 & $1,00 \%$ & $1,00 \%$ & $49,90 \%$ & $51,60 \%$ & $53,10 \%$ & $55,00 \%$ & $57,20 \%$ & $59,10 \%$ & $60,70 \%$ & $58,70 \%$ \\
\hline 5 & $1,00 \%$ & $1,00 \%$ & $39,80 \%$ & $41,30 \%$ & $44,50 \%$ & $46,90 \%$ & $50,80 \%$ & $54,60 \%$ & $58,30 \%$ & $54,30 \%$ \\
\hline 6 & $1,00 \%$ & $1,00 \%$ & $35,00 \%$ & $39,10 \%$ & $42,20 \%$ & $44,60 \%$ & $47,90 \%$ & $50,90 \%$ & $53,30 \%$ & $50,20 \%$ \\
\hline 7 & $1,00 \%$ & $1,00 \%$ & $13,10 \%$ & $14,40 \%$ & $16,50 \%$ & $17,90 \%$ & $20,40 \%$ & $22,80 \%$ & $25,10 \%$ & $22,60 \%$ \\
\hline 8 & $1,00 \%$ & $1,00 \%$ & $18,10 \%$ & $19,50 \%$ & $21,20 \%$ & $23,20 \%$ & $25,90 \%$ & $28,40 \%$ & $30,30 \%$ & $27,80 \%$ \\
\hline 9 & $1,00 \%$ & $1,00 \%$ & $113,80 \%$ & $125,40 \%$ & $143,70 \%$ & $159,60 \%$ & $184,60 \%$ & $209,00 \%$ & $230,90 \%$ & $206,00 \%$ \\
\hline 10 & $1,00 \%$ & $1,00 \%$ & $47,60 \%$ & $57,70 \%$ & $86,70 \%$ & $106,10 \%$ & $136,10 \%$ & $159,90 \%$ & $179,40 \%$ & $154,00 \%$ \\
\hline 11 & $1,00 \%$ & $1,00 \%$ & $36,00 \%$ & $43,30 \%$ & $53,00 \%$ & $59,10 \%$ & $68,10 \%$ & $77,60 \%$ & $85,90 \%$ & $76,40 \%$ \\
\hline 12 & $1,00 \%$ & $1,00 \%$ & $10,00 \%$ & $22,70 \%$ & $35,40 \%$ & $45,80 \%$ & $59,10 \%$ & $70,50 \%$ & $79,50 \%$ & $67,80 \%$ \\
\hline 13 & $1,00 \%$ & $1,00 \%$ & $27,00 \%$ & $31,10 \%$ & $36,80 \%$ & $41,90 \%$ & $49,50 \%$ & $57,60 \%$ & $65,40 \%$ & $57,20 \%$ \\
\hline 14 & $1,00 \%$ & $1,00 \%$ & $9,10 \%$ & $16,20 \%$ & $25,90 \%$ & $33,50 \%$ & $44,80 \%$ & $55,40 \%$ & $65,50 \%$ & $54,50 \%$ \\
\hline 15 & $1,00 \%$ & $1,00 \%$ & $3,10 \%$ & $4,90 \%$ & $7,00 \%$ & $8,90 \%$ & $11,90 \%$ & $15,10 \%$ & $18,20 \%$ & $14,90 \%$ \\
\hline 16 & $1,00 \%$ & $1,00 \%$ & $-3,00 \%$ & $-0,70 \%$ & $3,10 \%$ & $5,80 \%$ & $10,40 \%$ & $15,20 \%$ & $19,00 \%$ & $14,50 \%$ \\
\hline 17 & $1,00 \%$ & $1,00 \%$ & $43,90 \%$ & $47,30 \%$ & $52,50 \%$ & $55,80 \%$ & $61,20 \%$ & $66,40 \%$ & $70,70 \%$ & $65,50 \%$ \\
\hline 18 & $1,00 \%$ & $1,00 \%$ & $18,80 \%$ & $27,30 \%$ & $34,90 \%$ & $41,80 \%$ & $49,10 \%$ & $54,40 \%$ & $58,50 \%$ & $52,60 \%$ \\
\hline 19 & $1,00 \%$ & $1,00 \%$ & $13,20 \%$ & $14,40 \%$ & $16,50 \%$ & $18,70 \%$ & $21,30 \%$ & $23,50 \%$ & $25,80 \%$ & $23,30 \%$ \\
\hline 20 & $1,00 \%$ & $1,00 \%$ & $1,00 \%$ & $6,40 \%$ & $11,30 \%$ & $14,90 \%$ & $19,10 \%$ & $22,30 \%$ & $25,30 \%$ & $21,50 \%$ \\
\hline
\end{tabular}

A Tabela 8, quando comparada à Tabela 7 , mostra que existe pouca sensibilidade à volatilidade das taxas de juros. O retorno da cota sênior foi sempre igual à taxa indicativa de CDI $+1 \%$ a.a. O retorno da cota subordinada foi inferior a $100 \%$ do CDI no percentil 1\% nas simulações do tipo 16 e 20. 
Tabela 8

Resultado da simulação - bloco II

\begin{tabular}{|c|c|c|c|c|c|c|c|c|c|c|}
\hline \multirow{3}{*}{$\begin{array}{c}\text { Tipo } \\
\text { de } \\
\text { simulação }\end{array}$} & \multicolumn{2}{|c|}{$\begin{array}{c}\text { Cota } \\
\text { sênior }\end{array}$} & \multicolumn{8}{|c|}{$\begin{array}{c}\text { Cota } \\
\text { subordinada }\end{array}$} \\
\hline & \multirow{2}{*}{\begin{tabular}{|c|} 
Percentil \\
$1 \%$
\end{tabular}} & \multirow{2}{*}{ Média } & \multicolumn{4}{|c|}{ Percentil } & \multicolumn{3}{|c|}{ Quartil } & \multirow[b]{2}{*}{ Média } \\
\hline & & & $1 \%$ & $2 \%$ & $5 \%$ & $10 \%$ & $1^{\circ}$ & $2^{\circ}$ & $3^{0}$ & \\
\hline 1 & $1,00 \%$ & $1,00 \%$ & $94,60 \%$ & $98,20 \%$ & $103,00 \%$ & $106,50 \%$ & $112,60 \%$ & $118,30 \%$ & $123,50 \%$ & $117,70 \%$ \\
\hline 2 & $1,00 \%$ & $1,00 \%$ & $72,70 \%$ & $75,00 \%$ & $78,00 \%$ & $80,60 \%$ & $84,50 \%$ & $88,00 \%$ & $91,00 \%$ & $87,40 \%$ \\
\hline 3 & $1,00 \%$ & $1,00 \%$ & $49,60 \%$ & $50,70 \%$ & $53,80 \%$ & $56,20 \%$ & $59,70 \%$ & $64,00 \%$ & $67,70 \%$ & $63,60 \%$ \\
\hline 4 & $1,00 \%$ & $1,00 \%$ & $46,80 \%$ & $48,40 \%$ & $50,60 \%$ & $52,80 \%$ & $55,80 \%$ & $58,90 \%$ & $61,40 \%$ & $58,40 \%$ \\
\hline 5 & $1,00 \%$ & $1,00 \%$ & $27,40 \%$ & $30,50 \%$ & $37,30 \%$ & $41,60 \%$ & $47,60 \%$ & $54,00 \%$ & $59,90 \%$ & $53,30 \%$ \\
\hline 6 & $1,00 \%$ & $1,00 \%$ & $31,30 \%$ & $33,60 \%$ & $38,60 \%$ & $41,70 \%$ & $46,30 \%$ & $50,20 \%$ & $54,00 \%$ & $49,70 \%$ \\
\hline 7 & $1,00 \%$ & $1,00 \%$ & $6,20 \%$ & $8,70 \%$ & $11,80 \%$ & $14,70 \%$ & $18,50 \%$ & $22,60 \%$ & $26,00 \%$ & $22,10 \%$ \\
\hline 8 & $1,00 \%$ & $1,00 \%$ & $13,40 \%$ & $15,80 \%$ & $18,80 \%$ & $21,00 \%$ & $24,50 \%$ & $27,90 \%$ & $30,80 \%$ & $27,40 \%$ \\
\hline 9 & $1,00 \%$ & $1,00 \%$ & $106,60 \%$ & $122,00 \%$ & $143,60 \%$ & $158,00 \%$ & $183,00 \%$ & $210,30 \%$ & $232,50 \%$ & $206,70 \%$ \\
\hline 10 & $1,00 \%$ & $1,00 \%$ & $48,90 \%$ & $71,80 \%$ & $93,10 \%$ & $112,60 \%$ & $136,70 \%$ & $161,10 \%$ & $180,70 \%$ & $156,00 \%$ \\
\hline 11 & $1,00 \%$ & $1,00 \%$ & $39,30 \%$ & $45,00 \%$ & $52,60 \%$ & $58,00 \%$ & $68,60 \%$ & $77,40 \%$ & $85,70 \%$ & $76,30 \%$ \\
\hline 12 & $1,00 \%$ & $1,00 \%$ & $9,20 \%$ & $18,60 \%$ & $35,40 \%$ & $45,10 \%$ & $58,50 \%$ & $70,60 \%$ & $80,20 \%$ & $67,90 \%$ \\
\hline 13 & $1,00 \%$ & $1,00 \%$ & $23,20 \%$ & $28,40 \%$ & $35,40 \%$ & $40,20 \%$ & $48,50 \%$ & $57,10 \%$ & $65,80 \%$ & $56,90 \%$ \\
\hline 14 & $1,00 \%$ & $1,00 \%$ & $11,70 \%$ & $18,00 \%$ & $25,20 \%$ & $33,10 \%$ & $44,00 \%$ & $55,50 \%$ & $67,00 \%$ & $54,90 \%$ \\
\hline 15 & $1,00 \%$ & $1,00 \%$ & $1,90 \%$ & $3,20 \%$ & $5,60 \%$ & $7,80 \%$ & $11,00 \%$ & $14,80 \%$ & $18,30 \%$ & $14,50 \%$ \\
\hline 16 & $1,00 \%$ & $1,00 \%$ & $-3,40 \%$ & $-0,80 \%$ & $1,80 \%$ & $5,20 \%$ & $9,60 \%$ & $15,00 \%$ & $19,40 \%$ & $14,40 \%$ \\
\hline 17 & $1,00 \%$ & $1,00 \%$ & $37,30 \%$ & $40,90 \%$ & $46,90 \%$ & $51,10 \%$ & $58,00 \%$ & $65,50 \%$ & $72,10 \%$ & $64,70 \%$ \\
\hline 18 & $1,00 \%$ & $1,00 \%$ & $18,00 \%$ & $26,40 \%$ & $32,90 \%$ & $38,20 \%$ & $46,50 \%$ & $54,00 \%$ & $60,30 \%$ & $52,70 \%$ \\
\hline 19 & $1,00 \%$ & $1,00 \%$ & $7,70 \%$ & $10,40 \%$ & $13,60 \%$ & $16,00 \%$ & $19,60 \%$ & $23,00 \%$ & $26,60 \%$ & $22,80 \%$ \\
\hline 20 & $1,00 \%$ & $1,00 \%$ & $-3,50 \%$ & $2,20 \%$ & $8,70 \%$ & $12,30 \%$ & $17,10 \%$ & $22,30 \%$ & $26,10 \%$ & $21,20 \%$ \\
\hline
\end{tabular}

A Tabela 9 mostra que o cotista sênior recebeu a remuneração indicativa, com $99 \%$ de certeza. Quanto às cotas subordinadas, embora os ativos com maiores volatilidades para a taxa de inadimplência apresentem os piores resultados, mesmo assim é possível generalizar e afirmar que a probabilidade de que seu retorno seja superior à taxa do CDI está próxima a 95\%. Note-se, na simulação 18, que a remuneração média do cotista sênior foi ligeiramente inferior a $1 \%$, do que se conclui que em pelo menos uma simulação entre as 2.000 o cotista subordinado não recuperou o valor aplicado. 
Tabela 9

Resultado da simulação - bloco III

\begin{tabular}{|c|c|c|c|c|c|c|c|c|c|c|}
\hline \multirow{3}{*}{$\begin{array}{c}\text { Tipo } \\
\text { de } \\
\text { simulação }\end{array}$} & \multicolumn{2}{|c|}{$\begin{array}{c}\text { Cota } \\
\text { sênior }\end{array}$} & \multicolumn{8}{|c|}{$\begin{array}{c}\text { Cota } \\
\text { subordinada }\end{array}$} \\
\hline & \multirow{2}{*}{$\begin{array}{c}\text { Percentil } \\
1 \%\end{array}$} & \multirow{2}{*}{ Média } & \multicolumn{4}{|c|}{ Percentil } & \multicolumn{3}{|c|}{ Quartil } & \multirow[b]{2}{*}{ Média } \\
\hline & & & $1 \%$ & $2 \%$ & $5 \%$ & $10 \%$ & $1^{\circ}$ & $2^{\circ}$ & $3^{\circ}$ & \\
\hline 1 & $1,00 \%$ & $1,00 \%$ & $97,80 \%$ & $101,10 \%$ & $105,40 \%$ & $109,10 \%$ & $113,80 \%$ & $118,20 \%$ & $122,00 \%$ & $117,50 \%$ \\
\hline 2 & $1,00 \%$ & $1,00 \%$ & $66,20 \%$ & $70,00 \%$ & $75,50 \%$ & $79,60 \%$ & $84,60 \%$ & $88,20 \%$ & $90,80 \%$ & $86,90 \%$ \\
\hline 3 & $1,00 \%$ & $1,00 \%$ & $51,70 \%$ & $53,30 \%$ & $56,20 \%$ & $58,20 \%$ & $61,40 \%$ & $64,10 \%$ & $66,60 \%$ & $63,70 \%$ \\
\hline 4 & $1,00 \%$ & $1,00 \%$ & $41,80 \%$ & $44,80 \%$ & $49,30 \%$ & $52,60 \%$ & $56,20 \%$ & $59,10 \%$ & $61,10 \%$ & $58,00 \%$ \\
\hline 5 & $1,00 \%$ & $1,00 \%$ & $32,00 \%$ & $34,80 \%$ & $39,60 \%$ & $44,20 \%$ & $49,50 \%$ & $54,70 \%$ & $58,70 \%$ & $53,70 \%$ \\
\hline 6 & $1,00 \%$ & $1,00 \%$ & $22,20 \%$ & $28,30 \%$ & $35,30 \%$ & $40,90 \%$ & $46,40 \%$ & $50,80 \%$ & $53,70 \%$ & $49,10 \%$ \\
\hline 7 & $1,00 \%$ & $1,00 \%$ & \begin{tabular}{|l|}
$8,70 \%$ \\
\end{tabular} & $10,90 \%$ & $13,90 \%$ & $16,00 \%$ & $19,40 \%$ & $22,50 \%$ & $25,20 \%$ & $22,00 \%$ \\
\hline 8 & $1,00 \%$ & $1,00 \%$ & $4,00 \%$ & $9,70 \%$ & $15,90 \%$ & $20,40 \%$ & $24,50 \%$ & $28,20 \%$ & $30,80 \%$ & $26,80 \%$ \\
\hline 9 & $1,00 \%$ & $1,00 \%$ & $35,90 \%$ & $63,20 \%$ & $103,50 \%$ & $129,90 \%$ & $173,20 \%$ & $210,00 \%$ & $241,40 \%$ & $201,90 \%$ \\
\hline 10 & $1,00 \%$ & $1,00 \%$ & $-38,30 \%$ & $-11,70 \%$ & $43,20 \%$ & $77,30 \%$ & $124,40 \%$ & $161,00 \%$ & $186,30 \%$ & $148,70 \%$ \\
\hline 11 & $1,00 \%$ & $1,00 \%$ & $12,00 \%$ & $21,70 \%$ & $38,00 \%$ & $48,80 \%$ & $64,10 \%$ & $78,00 \%$ & $89,50 \%$ & $75,10 \%$ \\
\hline 12 & $1,00 \%$ & $1,00 \%$ & $-37,90 \%$ & $-13,60 \%$ & $8,60 \%$ & $27,30 \%$ & $50,30 \%$ & $69,30 \%$ & $82,80 \%$ & $62,90 \%$ \\
\hline 13 & $1,00 \%$ & $1,00 \%$ & $9,30 \%$ & $15,70 \%$ & $26,00 \%$ & $33,00 \%$ & $45,50 \%$ & $58,30 \%$ & $69,40 \%$ & $57,00 \%$ \\
\hline 14 & $1,00 \%$ & $1,00 \%$ & $-12,60 \%$ & $-4,20 \%$ & $11,90 \%$ & $22,10 \%$ & $38,60 \%$ & $56,00 \%$ & $70,20 \%$ & $53,30 \%$ \\
\hline 15 & $1,00 \%$ & $1,00 \%$ & $-3,40 \%$ & $-1,50 \%$ & $2,30 \%$ & $5,10 \%$ & $10,10 \%$ & $14,90 \%$ & $19,30 \%$ & $14,40 \%$ \\
\hline 16 & $1,00 \%$ & $1,00 \%$ & $-17,20 \%$ & $-13,10 \%$ & $-5,50 \%$ & $0,30 \%$ & $7,70 \%$ & $14,80 \%$ & $20,90 \%$ & $13,40 \%$ \\
\hline 17 & $1,00 \%$ & $1,00 \%$ & $19,00 \%$ & $28,20 \%$ & $39,80 \%$ & $48,30 \%$ & $58,70 \%$ & $66,30 \%$ & $71,70 \%$ & $63,60 \%$ \\
\hline 18 & $1,00 \%$ & $0,90 \%$ & $-30,10 \%$ & $-6,20 \%$ & $17,30 \%$ & $30,50 \%$ & $45,30 \%$ & $54,20 \%$ & $59,20 \%$ & $48,90 \%$ \\
\hline 19 & $1,00 \%$ & $1,00 \%$ & $1,40 \%$ & $6,90 \%$ & $11,70 \%$ & $15,40 \%$ & $20,00 \%$ & $23,70 \%$ & $26,20 \%$ & $22,40 \%$ \\
\hline 20 & $1,00 \%$ & $1,00 \%$ & $-30,30 \%$ & $-18,60 \%$ & $-0,80 \%$ & $8,20 \%$ & $17,20 \%$ & $22,50 \%$ & $25,80 \%$ & $19,20 \%$ \\
\hline
\end{tabular}

A Tabela 10 mostra que, mesmo quando se introduz um deslocamento de 50\% nas taxas de inadimplência, o cotista sênior recebeu a remuneração indicativa de CDI $+1 \%$ a.a. com $99 \%$ de confiança. Quanto ao cotista subordinado, se o ativo é composto por duplicatas (simulações do tipo 13 a 16), a probabilidade de baixos retornos ou mesmo recuperação parcial do capital investido não pode ser desprezada. Para os demais ativos, a probabilidade de retornos acima do CDI é superior a $95 \%$, atingindo $99 \%$ em diversas situações. 


\begin{tabular}{|c|c|c|c|c|c|c|c|c|c|c|}
\hline \multirow{3}{*}{$\begin{array}{c}\text { Tipo } \\
\text { de } \\
\text { simulação }\end{array}$} & \multicolumn{2}{|c|}{$\begin{array}{c}\text { Cota } \\
\text { sênior }\end{array}$} & \multicolumn{8}{|c|}{$\begin{array}{c}\text { Cota } \\
\text { subordinada }\end{array}$} \\
\hline & \multirow{2}{*}{$\begin{array}{c}\text { Percentil } \\
1 \%\end{array}$} & \multirow{2}{*}{ Média } & \multicolumn{4}{|c|}{ Percentil } & \multicolumn{3}{|c|}{ Quartil } & \multirow[b]{2}{*}{ Média } \\
\hline & & & $1 \%$ & $2 \%$ & $5 \%$ & $10 \%$ & $1^{\circ}$ & $2^{\circ}$ & $3^{0}$ & \\
\hline 1 & $1,00 \%$ & $1,00 \%$ & $94,90 \%$ & $97,80 \%$ & $102,10 \%$ & $104,70 \%$ & $109,40 \%$ & $113,40 \%$ & $117,20 \%$ & $113,00 \%$ \\
\hline 2 & $1,00 \%$ & & $68,90 \%$ & $72,10 \%$ & $75,40 \%$ & $78,30 \%$ & $82,10 \%$ & $85,20 \%$ & $87,80 \%$ & $84,50 \%$ \\
\hline 3 & $00 \%$ & $1,00 \%$ & $49,50 \%$ & $51,10 \%$ & $53,60 \%$ & $55,10 \%$ & $58,00 \%$ & $60,70 \%$ & $63,20 \%$ & $0 \%$ \\
\hline 4 & $0 \%$ & $1,00 \%$ & $41,80 \%$ & $44,10 \%$ & $48,20 \%$ & $50,50 \%$ & $53,80 \%$ & $56,60 \%$ & $59,00 \%$ & \\
\hline 5 & $1,00 \%$ & $1,00 \%$ & $26,70 \%$ & $29,80 \%$ & $34,20 \%$ & $37,40 \%$ & $43,20 \%$ & $48,20 \%$ & $52,80 \%$ & $50 \%$ \\
\hline 6 & $1,00 \%$ & $1,00 \%$ & $24,10 \%$ & $27,80 \%$ & $34,00 \%$ & $37,40 \%$ & $42,50 \%$ & $46,70 \%$ & $49,90 \%$ & $45,60 \%$ \\
\hline 7 & $1,00 \%$ & $1,00 \%$ & $5,80 \%$ & $7,90 \%$ & $9,90 \%$ & $12,00 \%$ & $15,20 \%$ & $18,50 \%$ & $21,50 \%$ & $18,20 \%$ \\
\hline 8 & $0 \%$ & $1,00 \%$ & $6,60 \%$ & $10,00 \%$ & $13,80 \%$ & $17,30 \%$ & $21,10 \%$ & $24,80 \%$ & $27,40 \%$ & $90 \%$ \\
\hline 9 & $0 \%$ & $1,00 \%$ & $24,20 \%$ & $38,40 \%$ & $62,50 \%$ & $80,90 \%$ & $115,50 \%$ & $148,50 \%$ & $177,10 \%$ & $50 \%$ \\
\hline 10 & $1,00 \%$ & $1,00 \%$ & $-47,40 \%$ & $-27,20 \%$ & $12,60 \%$ & $38,60 \%$ & $78,30 \%$ & $115,00 \%$ & $142,00 \%$ & $30 \%$ \\
\hline 11 & $1,00 \%$ & $1,00 \%$ & $2,80 \%$ & $8,50 \%$ & $16,60 \%$ & $25,00 \%$ & $39,60 \%$ & $52,90 \%$ & $64,40 \%$ & $90 \%$ \\
\hline 12 & $1,00 \%$ & $1,00 \%$ & $-36,40 \%$ & $-23,10 \%$ & $-3,00 \%$ & $11,30 \%$ & $30,90 \%$ & $49,80 \%$ & $63,40 \%$ & $44,90 \%$ \\
\hline 13 & $1,00 \%$ & $1,00 \%$ & $-13,90 \%$ & $-10,10 \%$ & $-3,90 \%$ & $2,00 \%$ & $12,50 \%$ & $22,50 \%$ & $32,20 \%$ & $0 \%$ \\
\hline 14 & $1,00 \%$ & $1,00 \%$ & $-29,20 \%$ & $-22,50 \%$ & $-13,50 \%$ & $-4,50 \%$ & $9,00 \%$ & $22,00 \%$ & $35,60 \%$ & $21,30 \%$ \\
\hline 15 & $1,00 \%$ & $1,00 \%$ & $-14,40 \%$ & $-13,00 \%$ & $-10,00 \%$ & $-7,90 \%$ & $-3,40 \%$ & $1,10 \%$ & $5,30 \%$ & $0,80 \%$ \\
\hline 16 & $1,00 \%$ & $1,00 \%$ & $-25,30 \%$ & $-20,30 \%$ & $-15,80 \%$ & $-12,00 \%$ & $-5,80 \%$ & $0,70 \%$ & $6,50 \%$ & $0,10 \%$ \\
\hline 17 & $1,00 \%$ & $1,00 \%$ & $26,00 \%$ & $32,20 \%$ & $38,50 \%$ & $45,60 \%$ & $53,30 \%$ & $60,30 \%$ & $65,50 \%$ & $58,60 \%$ \\
\hline 18 & $1,00 \%$ & $1,00 \%$ & $0,80 \%$ & $10,50 \%$ & $23,90 \%$ & $31,40 \%$ & $41,90 \%$ & $49,70 \%$ & $55,30 \%$ & $46,90 \%$ \\
\hline 19 & $1,00 \%$ & $1,00 \%$ & $4,70 \%$ & $7,50 \%$ & $10,80 \%$ & $13,40 \%$ & $17,20 \%$ & $20,60 \%$ & $23,50 \%$ & $19,90 \%$ \\
\hline 20 & $1,00 \%$ & $1,00 \%$ & $-6,60 \%$ & $-1,90 \%$ & $4,30 \%$ & $9,20 \%$ & $15,10 \%$ & $19,90 \%$ & $23,20 \%$ & $18,30 \%$ \\
\hline
\end{tabular}

Com base nos resultados obtidos, as seguintes conclusões podem ser extraídas:

a) Em todas as simulações a cota sênior obteve a remuneração indicativa com 99\% de certeza; daí conclui-se que o risco para o investidor adquirente de cotas seniores é muito baixo.

b) Em condições normais, em que as volatilidades são aquelas de fato observadas e quando não se introduz nenhum fator de "stress", a cota subordinada obtém remuneração superior à taxa do CDI com 99\% de certeza, com a exceção de apenas uma simulação, cuja confiança está entre $95 \%$ e $98 \%$. Logo, conclui-se que, em situações normais que não configurem alteração de regime, o risco para o adquirente de cotas subordinadas também é baixo.

c) A sensibilidade à taxa do CDI mostrou-se baixa, a ponto de mesmo quando se dobra sua volatilidade, o retorno da cota subordinada será superior à taxa do CDI com $99 \%$ de certeza. Nas duas exceções observadas, esta probabilidade caiu para 95\%. Conclui-se daí que, dentro de um cenário de estabilidade econômica em que os juros sejam estáveis, este fator de risco é secundário.

d) Ao se introduzir fatores de stress sobre o nível das taxas de perda por inadimplência ou sobre sua volatilidade, reduz-se o índice de confiança para que o retorno da cota subordinada seja superior à taxa do CDI. A Tabela 11 resume as estatísticas com fatores de stress: 
Tabela 11

Retorno da cota subordinada em função do fator de stress

\begin{tabular}{l|c|c|c|c}
\hline \multicolumn{1}{c|}{$\begin{array}{c}\text { Fator de } \\
\text { stress }\end{array}$} & $\begin{array}{c}\text { Remuneração } \\
\text { Média }\end{array}$ & $\begin{array}{c}\text { Média do } \\
\text { Percentil 1\% }\end{array}$ & $\begin{array}{c}\text { Média do } \\
\text { Percentil 2\% }\end{array}$ & $\begin{array}{c}\text { Média do } \\
\text { Percentil 5\% }\end{array}$ \\
\hline Nenhum (Bloco I) & $65 \%$ & $36 \%$ & $40 \%$ & $47 \%$ \\
\hline Volatilidade dos juros (Bloco II) & $64 \%$ & $32 \%$ & $37 \%$ & $44 \%$ \\
\hline Volatilidade das perdas (Bloco III) & $63 \%$ & $12 \%$ & $21 \%$ & $34 \%$ \\
\hline Nível de perda (Bloco IV) & $49 \%$ & $10 \%$ & $16 \%$ & $25 \%$ \\
\hline Média geral & $60 \%$ & $22 \%$ & $29 \%$ & $38 \%$ \\
\hline
\end{tabular}

e) Olhando sob a ótica da modalidade da operação, algumas delas mostram-se menos suscetíveis a apresentar retornos insatisfatórios para o cotista subordinado. O crédito pessoal, por exemplo, mostrou elevada margem líquida, baixas taxa e volatilidade de perda por inadimplência, portanto, este foi o ativo com melhores resultados. Em oposição, o desconto de duplicatas, por ter apresentado reduzida margem líquida e elevadas taxa e volatilidade de perda por inadimplência, foi o ativo que proporcionou a pior remuneração para a cota subordinada. A Tabela 12 resume as estatísticas de retorno por modalidade de operação de crédito, sem a introdução de fatores de stress.

Tabela 12

Retorno da cota subordinada por modalidade de operação de crédito

\begin{tabular}{lcccc}
\hline \multicolumn{1}{c|}{ Ativo } & Remuneração & Média do & Média do & Média do \\
\hline & Média & Percentil 1\% & Percentil 2\% & Percentil 5\% \\
\hline Crédito pessoal & $81 \%$ & $66 \%$ & $69 \%$ & $72 \%$ \\
\hline CDC Veículos PF & $37 \%$ & $20 \%$ & $23 \%$ & $27 \%$ \\
\hline CDC outros PF & $115 \%$ & $20 \%$ & $35 \%$ & $58 \%$ \\
\hline Desconto de duplicatas & $29 \%$ & $-2 \%$ & $2 \%$ & $8 \%$ \\
\hline Capital de giro & $39 \%$ & $8 \%$ & $15 \%$ & $23 \%$ \\
\hline Média geral & $60 \%$ & $22 \%$ & $29 \%$ & $38 \%$ \\
\hline
\end{tabular}

f) É importante notar que as piores situações ocorrem quando se testa o prazo maior, pois a dispersão da taxa de perda alcança maiores valores. Da mesma forma, carteiras com menor percentual de recebíveis em sua composição apresentam pior desempenho. A Tabela 13 e a Tabela 14 resumem as estatísticas sobre o retorno da cota subordinada para diferentes prazos e diferentes percentuais de composição de carteira, respectivamente, sem a introdução de fatores de stress.

Tabela 13

Retorno da cota subordinada em função do prazo dos ativos

\begin{tabular}{l|c|c|c|c}
\hline Prazo & $\begin{array}{c}\text { Remuneração } \\
\text { Média }\end{array}$ & $\begin{array}{c}\text { Média do } \\
\text { Percentil 1\% }\end{array}$ & $\begin{array}{c}\text { Média do } \\
\text { Percentil 2\% }\end{array}$ & $\begin{array}{c}\text { Média do } \\
\text { Percentil 5\% }\end{array}$ \\
\hline Maior & $55 \%$ & $12 \%$ & $20 \%$ & $30 \%$ \\
\hline Menor & $66 \%$ & $33 \%$ & $38 \%$ & $45 \%$ \\
\hline Média geral & $60 \%$ & $22 \%$ & $29 \%$ & $38 \%$ \\
\hline
\end{tabular}




\begin{tabular}{c|c|c|c|c}
\hline $\begin{array}{c}\% \text { de } \\
\text { recebíveis }\end{array}$ & $\begin{array}{c}\text { Remuneração } \\
\text { Média }\end{array}$ & $\begin{array}{c}\text { Média do } \\
\text { Percentil 1\% }\end{array}$ & $\begin{array}{c}\text { Média do } \\
\text { Percentil 2\% }\end{array}$ & $\begin{array}{c}\text { Média do } \\
\text { Percentil 5\% }\end{array}$ \\
\hline $50 \%$ & $36 \%$ & $11 \%$ & $15 \%$ & $21 \%$ \\
\hline $100 \%$ & $84 \%$ & $34 \%$ & $42 \%$ & $54 \%$ \\
\hline Média geral & $60 \%$ & $22 \%$ & $29 \%$ & $38 \%$ \\
\hline
\end{tabular}

g) Os itens (b), (c), (d), (e) e (f) induzem à conclusão de que, em condições normais, o originador tem baixíssimo risco ao adquirir cotas subordinadas, com elevado grau de confiança. A hipótese de obtenção de retorno abaixo da taxa básica de juros ou mesmo da não recuperação parcial ou total do capital aplicado só é possível se for admitida uma brusca mudança nos fatores de risco, e mesmo assim em situações isoladas.

h) As constatações obtidas em (g) também são válidas para as instituições financeiras que detêm cotas subordinadas. Estas constatações indicam que o BACEN foi muito conservador ao estabelecer que os ativos securitizados sejam mantidos no balanço das instituições, pois despreza qualquer transferência de riscos feita ao investidor. De fato, as cotas subordinadas são uma barreira às perdas por inadimplência da carteira; no entanto, a norma não considera o fato de que praticamente todo o resultado de intermediação foi transferido ao originador, cabendo ao investidor em cotas sênior um retorno pouco superior ao benchmark (o CDI). É importante lembrar que, no apreçamento de operações de crédito, a perspectiva de perdas provenientes da inadimplência representa uma das principais componentes da taxa de juros, e o excess spread constitui-se, de fato, na primeira barreira às perdas. Portanto, a norma desconsidera por completo o efeito mitigador proporcionado pela elevada margem líquida dos ativos que compõem o balanço do fundo e seu reflexo no retorno das cotas subordinadas. Sob a ótica da solvência das instituições financeiras, a norma requer capital suficiente para fazer frente aos riscos, mas, se o patrimônio requerido for excessivo o sistema bancário será desestimulado quanto ao uso da securitização como alternativa de financiamento dos ativos.

\section{Conclusões}

As simulações realizadas indicaram que a hipótese de que o cotista sênior venha a receber remuneração inferior àquela indicativa é remotíssima, mesmo em condições de stress. Portanto, o risco para o investidor em cotas sênior é muito baixo, justificando as elevadas classificações creditícias que as agências de rating atribuem ao investimento nessas cotas. Esta afirmação é válida para qualquer cenário estudado. 
Para o originador dos ativos, isto é, o cedente dos créditos, que usualmente adquire cotas subordinadas para viabilizar o fundo, as simulações mostraram que o risco de retornos inferiores à taxa de juros de mercado é também consideravelmente baixo, graças ao elevado spread embutido na taxa de juros dos ativos. Dentro de condições de normalidade de cenário, todos os tipos de simulação apresentaram retornos superiores à taxa do CDI em $99 \%$ das vezes, com uma exceção a $95 \%$. Dentro de condições de stress, a remuneração média da cota subordinada dos 20 tipos de simulação mostrou-se superior à taxa do CDI no percentil 1\%, embora alguns ativos, dentro de determinadas condições, tenham apresentado retornos inferiores ao benchmark. Com base nos resultados, é razoável afirmar que o risco para o originador é baixo.

É importante ressaltar que estas simulações refletem as condições do mercado financeiro em um dado período, e características específicas de fundos, dentre as quais o tipo de ativo financeiro securitizado. Assim, se os FIDC passarem a ser estruturados com características muito distintas daquelas consideradas, ou se o nível de inadimplência vier a subir substancialmente no futuro, ou se o spread bancário vier a cair significativamente, ou mesmo se as volatilidades para taxa de juros e inadimplência forem muito diferentes, as conclusões aqui apresentadas podem não permanecer válidas.

Para as instituições financeiras que carregam cotas subordinadas em seu ativo fica evidente que o Banco Central adotou regulamentação muito conservadora ao desconsiderar qualquer transferência de risco para o investidor, o que pode provocar ineficiência alocativa entre os agentes. É importante mencionar que o excesso de conservadorismo pode desestimular o uso da securitização, particularmente entre os bancos de pequeno e médio porte, o que gera a redução da oferta de crédito na economia.

Como metodologia de suficiência patrimonial, o BACEN poderia adotar regras similares àquelas sugeridas pelo BIS, considerando o rating e outras características dos instrumentos subordinados, ou desenvolvendo modelos de avaliação de riscos, baseados nas seguintes variáveis: percentuais de cotas de menor e de igual subordinação sobre o patrimônio do fundo, margem líquida excedente embutida na taxa de remuneração dos créditos, grau de diversificação dos ativos, taxa de inadimplência dos ativos, e outras variáveis que se mostrarem relevantes.

Com relação a trabalhos futuros a serem desenvolvidos, este artigo sugere a elaboração de estudos de correlação entre a pontualidade com que o tomador executa o pagamento de seus débitos e as características de cada modalidade de operação de crédito, como mercado-alvo, tipo de colaterização, liquidez das garantias, processo de contratação, de formalização, dentre outras. Esses estudos seriam de grande utilidade para toda a empresa que concede crédito.

Finalmente, é importante mencionar que, embora os FIDC tenham apresentado baixo risco ao investidor e ao Sistema Financeiro, é fundamental que bancos, agências de rating, e autoridades de supervisão e de regulação estejam atentos ao cumprimento de suas responsabilidades. A securitização não prescinde de um am- 
biente normativo adequado e da manutenção de boas práticas em termos de gestão financeira, ou corre-se o risco de repetir os mesmos erros que levaram os Estados Unidos à Crise do Subprime. Estas providências incluem: a necessidade de rigor na concessão de crédito por parte dos agentes financeiros; a corresponsabilização de alguns prestadores de serviços, como agências de rating e firmas de auditoria; um arcabouço normativo capaz de garantir que todas as instituições financeiras possuam patrimônio líquido compatível com seu nível de riscos; normas para a classificação dos créditos e de constituição de provisões; eficácia do processo de supervisão bancária; e a necessidade de ações pró-ativas quando as variáveis macro-econômicas indicarem a possibilidade de problemas à frente.

\section{Referências}

Banco Central Do Brasil (2001). Resolução CMN nº 2907. Brasília.

Banco Central Do Brasil (2008a). Circular no 3360. Brasília.

Banco Central Do Brasil (2008b). Resolução CMN no 3533. Brasília.

Bank for International Settlements - BIS (2006). Basle committee on banking supervision. International Convergence of Capital Measurement and Capital Standards: a Revised Framework. Basle.

Bodie, Z., Kane, A., \& Marcus, A. J. (2000). Fundamentos de Investimentos. Bookman, Porto Alegre.

Carneiro, D. D. \& Goldfajn, I. (2000). A securitização de hipotecas no Brasil. Rio de Janeiro, Junho de 2000. Texto para Discussão No 426. Pontifícia Universidade Católi-ca do Rio de janeiro, Departamento de Economia.

Fabozzi Jr., F. J., Davis, H. A., \& Choudhry, M. (2006). Introduction to Structured Finance. John Wiley Trade, New Jersey.

Ferreira, C. I. (2007). Securitização de ativos - A era da desintermediação financeira. Gainvest Publicações, Porto Alegre.

Greenbaum, S. I. \& Thakor, A. V. (1987). Bank funding modes. Journal of Banking and Finance, 11:379-401.

Jorion, P. (1998). Value at Risk. BM\&F, São Paulo.

Kothari, V. (2006). Securitization - The Financial Instrument of the Future. John Wiley \& Sons, Asia.

Longerstaey, J. \& Spencer, M. (1996). Riskmetrics ${ }^{T M}$. J.P. Morgan/Reuters, New York, 4th edition. 
Ranieri, L. S. (1996). The origins of securitizaion, sources of its growth, and its future potential. In Kendall, L. T. \& Fishman, M. J., editors, A Primer on Securitization. The MIT Press, London.

Rosenthal, J. A. \& Ocampo, J. M. (1988). Securitization of Credit: Inside the New Technology of Finance. John Wiley \& Sons, New Jersey. 